\title{
National Blend of Models: A Statistically Post-Processed Multi-Model Ensemble
}

\author{
JEFFREY P. CRAVEN, DAVID E. RUDACK, and PHILLIP E. SHAFER \\ Meteorological Development Laboratory. Silver Spring, $M D$
}

(Manuscript received 27 June 2019; review completed 22 October 2019)

\begin{abstract}
The National Blend of Models (NBM) is the culmination of an effort to develop a nationally consistent set of foundational gridded guidance products based on well-calibrated National Weather Service (NWS) and non-NWS model information. These guidance products are made available to the National Centers for Environmental Prediction centers and NWS Weather Forecast Offices for use in their forecast process. As the NWS continues to shift emphasis from production of forecast products to impact-based decision support services for core partners, the deterministic and probabilistic output from the NBM will become increasingly important as a starting point to the forecast process. The purpose of this manuscript is to document the progress of NBM versions 3.1 and 3.2 and what techniques are used to blend roughly 30 individual models and ensembles for a number of forecast elements and regions. Focus will be on the core elements such as (1) temperature and dew point temperature, (2) winter weather, fire weather, thunderstorm probabilities, and (3) wind speed and gusts.
\end{abstract}

\section{Introduction}

The National Weather Service (NWS) has been issuing gridded forecast products using the National Digital Forecast Database (NDFD, Glahn and Ruth, 2003) for nearly two decades. During this time, there has been a gradual evolution from initializing gridded forecasts using individual models such as the North American Mesoscale Model (NAM), the Global Forecast System (GFS), and GFS gridded model output statistics (MOS-GMOS) (Glahn et al. 2009) to using blends of various guidance. This evolution was inspired by the success of using a consensus of models (Vislocky and Fritsch, 1995; Baars and Mass, 2005; Whitaker et al., 2006; Goerss 2007a) to produce more accurate forecasts. The National Hurricane Center has a long history of using a consensus of numerical weather prediction (NWP) solutions to forecast the track of tropical cyclones and this has led to other similar efforts within the NWS.

The NWS Central Region Gridded Methodology Advisory Team (CRGMAT) developed the consensus blends (Gagan, 2009), which eventually led to the use of "AllBlend" for a common starting point for gridded Day 4-7 forecasts every 12 hours in 2011. AllBlend was a combination of $50 \%$ of the previous official NDFD forecast, and $50 \%$ of an equally weighted "consensus" blend (CONSAll) of raw model (CONSRaw) and MOS gridded (CONSMOS) forecasts. There were also bias corrected (BC) versions of the above, where 30 day linear regression was used to adjust to a gridded ground truth (BCCONSRaw, BCCONSMOS, BCCONSAll). Later, an improved blend (SuperBlend - Greif et al, 2017) was implemented and used as a starting point for Day's 2-7 forecast around 2016, using a combination of blended forecast inputs. The success of this project led to funding of the National Blend of Models (NBM) project in 2013. The Disaster Relief Appropriations Act of 2013 (commonly referred to as The Sandy Supplemental) funded the NBM in 2013 to replace regional blends and create a nationally consistent starting point from which grids could be adjusted as necessary.

Early versions of the NBM were released in January 2016 (v1.0), November 2016 (v2.0), July 2017 (v3.0), 
and October 2018 (v3.1). Development for v3.2 is underway with expected implementation by November 2019. Each successive version is dedicated to adding new weather elements and regions as required by the National Service Programs (Stern, 2018). NBM v3.2 has six total regions (Contiguous United States $\{$ CONUS Alaska, Hawaii, Guam, Puerto Rico, and Oceanic) and 65 weather elements.

This manuscript will cover the techniques used to produce most of the NBM elements except for Probability of Precipitation (PoP) and Quantitative Precipitation Forecasts (QPF) (for that please see Hamill et al., 2017 and Hamill and Scheuerer, 2018, for details on quantile mapping and dressing).

\section{Data and methods}

NBM v3.2 contains 31 different model systems that are blended to produce a single deterministic forecast product. For a growing number of elements, probabilistic forecasts are also created. Table 1 shows the daily inputs of each of the 24 hourly runs. Inputs from five different global modeling centers are present, including USA National Centers for Environmental Prediction (NCEP), Canadian Meteorological Center (CMC), Navy Fleet Numerical Operations Center (FNMOC), European Center for Medium Range Weather Forecasts (ECMWF), and Bureau of Meteorology (BoM) Australia. These span from high resolution convective allowing models such as the High Resolution Rapid Refresh (HRRR; Benjamin et al, 2016), to global ensembles such as the Global Ensemble Forecast System (GEFS; Zhou et al, 2017).

The NBM cycle time does not refer to the cycle times of the NWP cycle inputs but rather the cycle time at which the NBM is run For example, an NBM run at 1200 Coordinated Universal Time (UTC) does not include any NWP guidance from 1200 UTC. There is a data cutoff at forecast hour $(\mathrm{HH})-10$, or in this example 1150 UTC. The most recent model outputs available on the Weather and Climate Operational Supercomputer System (WCOSS) at 1150 UTC are included in the 1200 UTC NBM run. This includes both NCEP and non-NCEP NWP inputs; therefore, the 1200 UTC NBM contains several 0000 UTC and 0600 UTC inputs (details can be found in Table 1). For each subsequent hour the NBM is run there are at least four new NWP inputs out of the total of 31 possible data sources, while at 0700 UTC and 1900 UTC there are 10 new NWP inputs. Over a 24-hour period, each hour has an average of 7 new NWP inputs.

NBM v3.2 has six different forecast domains (see Fig. 1): (1) the CONUS at $2.5 \mathrm{~km},(2)$ Hawaii at $2.5 \mathrm{~km}$, (3) Alaska at $3 \mathrm{~km}$, (4) Puerto Rico at $1.25 \mathrm{~km}$, (5) Guam at $2.5 \mathrm{~km}$, and (6) the Oceanic Domain at $10 \mathrm{~km}$. NBM guidance is updated every hour at hourly time-steps for projections 1-36, with 3-hourly projections between 39-192 hours, and finally 6-hourly projections between 198-264 hours. Due to the sheer number of forecast elements and regions, we will not attempt to describe all of these to keep the length of the manuscript relatively concise.

A decaying average mean absolute error, $\mathrm{Bt}$, is calculated each day for each member of the NBM by equation (1) where $\alpha$ is a predefined decaying weight factor, FCSTt-1 is the most recent verifiable forecast, and OBSt-1, is its verifying observation. For the NBM, the Real Time Mesoscale Analysis (RTMA) and Unrestricted Real Time Mesoscale Analysis (URMA) (De Pondeca, 2011) are used as the ground truth observation.

$$
\mathrm{B}_{\mathrm{t}}=(1-\alpha) \mathrm{B}_{\mathrm{t}-1}+\alpha\left(\mathrm{FCST}_{\mathrm{t}-1}-\mathrm{OBS}_{\mathrm{t}-1}\right)
$$

The decaying weight factor in equation (1) (using alpha setting of 0.05 in NBM v3.1) determines the dynamic weighting value of the inputs (Cui et al, 2011). The final bias corrected forecast $\mathrm{BCFCST}_{t}$ is then simply defined as the difference between the most recent forecast FCST and the decaying average mean absolute error, $\mathrm{B}_{\mathrm{t}}$.

$$
\mathrm{BCFCST}_{t}=\left(\mathrm{FCST}_{\mathrm{t}}-\mathrm{B}_{\mathrm{t}}\right)
$$

The alpha setting in equation (1) was set to 0.05 for NBM v1.0, v2.0, v3.0, and v3.1, but was changed to 0.025 in NBM v3.2 for the 9 months of September through May to more closely match values used by NCEP (alpha of 0.02) and research at MDL (Glahn, 2013). During the stagnant summer months of 2019 (June, July, August), the alpha setting of 0.05 had less mean absolute error (MAE) so that value (same as NBM v3.1) will be left for those 3 months in v3.2 (which tend to have less dramatic regime changes compared to the colder months of the year).

A detailed discussion of the tradeoff of bias/variance when using exponentially weighted decaying average can be found in chapter 7 of Hamill, 2019. Use of the decaying average technique results in forecasts that can unrealistically vary from day to day and location to location, a consequence of the small training sample 
Table 1. The NBM v3.2 NWP inputs. * indicates inputs that provide wave model forecasts.

\begin{tabular}{|c|c|c|c|c|c|}
\hline Model input & Agency & Resolution & Cycles per day & Members & $\begin{array}{c}\text { Updates in NBM } \\
\text { cycle (UTC) }\end{array}$ \\
\hline ACCESS-R & BoM Australia & $11 \mathrm{~km}$ & $4 \mathrm{x}$ & 1 & $02,08,14,20$ \\
\hline ACCESS-G & BoM Australia & $35 \mathrm{~km}$ & $2 \mathrm{x}$ & 1 & 07,19 \\
\hline ECMWF* & ECMWF & $25 \mathrm{~km}$ & $2 \mathrm{x}$ & 1 & 08,20 \\
\hline ECMWFE* & ECMWF & $100 \mathrm{~km}$ & $2 \mathrm{x}$ & 50 & 09,21 \\
\hline EKDMOS & NCEP & $2.5 \mathrm{~km}$ & $4 \mathrm{x}$ & 1 & $07,11,19,23$ \\
\hline GDPS & CMC Canada & $25 \mathrm{~km}$ & $2 \mathrm{x}$ & 1 & 05,17 \\
\hline GEPS & CMC Canada & $50 \mathrm{~km}$ & $2 \mathrm{x}$ & 20 & 07,19 \\
\hline GEFS* & NCEP & $50 \mathrm{~km}$ & $4 \mathrm{x}$ & 20 & $00,06,12,18$ \\
\hline GFS* & NCEP & $13 \mathrm{~km}$ & $4 \mathrm{x}$ & 1 & $05,11,17,23$ \\
\hline GLMP & NCEP & $2.5 \mathrm{~km}$ & $24 \mathrm{x}$ & 1 & Every hour \\
\hline GMOS & NCEP & $2.5 \mathrm{~km}$ & $2 \mathrm{x}$ & 1 & 06,18 \\
\hline HiRes ARW & NCEP & $3 \mathrm{~km}$ & $2 \mathrm{x}$ & 1 & 04,16 \\
\hline HiRes ARW2 & NCEP & $3 \mathrm{~km}$ & $2 \mathrm{x}$ & 1 & 04,16 \\
\hline HiRes NMM & NCEP & $3 \mathrm{~km}$ & $2 \mathrm{x}$ & 1 & 04,16 \\
\hline HMON & NCEP & $1.5 \mathrm{~km}$ & $4 \mathrm{x}$ & 1 & $00,06,12,18$ \\
\hline HRRR & NCEP & $3 \mathrm{~km}$ & $24 \mathrm{x}$ & 2 & Every hour \\
\hline HWRF & NCEP & $1.5 \mathrm{~km}$ & $4 \mathrm{x}$ & 1 & $00,06,12,18$ \\
\hline NAM & NCEP & $12 \mathrm{~km}$ & $4 \mathrm{x}$ & 1 & $03,09,15,21$ \\
\hline NAMNest & NCEP & $3 \mathrm{~km}$ & $4 \mathrm{x}$ & 1 & $03,09,15,21$ \\
\hline NAVGEMD* & FNMOC & $50 \mathrm{~km}$ & $4 \mathrm{x}$ & 1 & $00,06,12,18$ \\
\hline NAVGEME* & FNMOC & $50 \mathrm{~km}$ & $2 \mathrm{x}$ & 20 & 06,18 \\
\hline RAP & NCEP & $13 \mathrm{~km}$ & $24 \mathrm{x}$ & 2 & Every hour \\
\hline RDPS & CMC Canada & $10 \mathrm{~km}$ & $4 \mathrm{x}$ & 1 & $04,10,16,22$ \\
\hline REPS & CMC Canada & $15 \mathrm{~km}$ & $2 \mathrm{x}$ & 20 & 07,19 \\
\hline SREF & NCEP & $16 \mathrm{~km}$ & $4 \mathrm{x}$ & 24 & $01,07,13,19$ \\
\hline
\end{tabular}

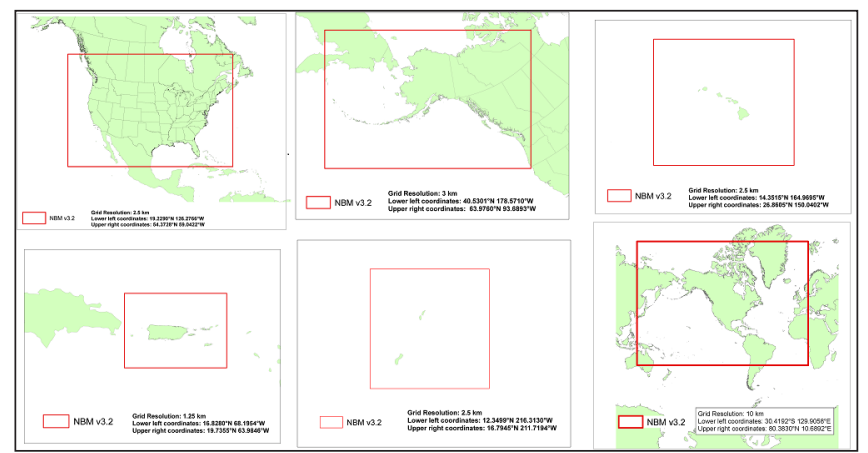

Figure 1. Domain maps from the six NBM sectors: CONUS (upper left), Alaska (upper center), Hawaii (upper right), Puerto Rico (lower left), Guam (lower center), and Oceanic (lower right). Click image for an external version; this applies to all figures and hereafter. size (especially as alpha values become larger). A comparison of the impact of bias correction to recent observations (over the past 10, 20, or 30 days) can be found in Table 2 . The relatively large alpha setting of NBM v3.1 (0.05) makes the bias correction behave more like 30 day linear regression bias corrected forecasts which are only influenced by the past 30 days of training data. Meanwhile, the alpha setting of 0.025 incorporates only $54 \%$ of the signal from the past 30 days and will correct the forecasts to a longer training sample.

Bias corrected NWP with lower MAE is given relatively high weights, while those with higher MAE are given correspondingly lower weights. These weights vary by weather element, grid point, cycle time, and forecast projection. Dynamic weighting is applied to maximum temperature, minimum 
Table 2. A comparison of the impact of recent observations on bias correction in the past 30 days based on alpha settings for exponentially weighted decaying average technique. Other linear regression based techniques used in NWS WFOs blended forecasts are provided for comparison. The order is based on highest to lowest influence of observations in the past 30 days.

\begin{tabular}{|c|c|c|c|}
\hline Alpha Setting/Blend & $\begin{array}{c}\text { \% influence Past 10 } \\
\text { Days }\end{array}$ & $\begin{array}{c}\text { \% influence Past 20 } \\
\text { Days }\end{array}$ & $\begin{array}{c}\text { \% influence Past 30 } \\
\text { Days }\end{array}$ \\
\hline BCCONSAll & 33 & 67 & 100 \\
\hline $0.05($ NBM v3.1) & 41 & 68 & 85 \\
\hline $0.025($ NBM v3.2) & 23 & 41 & 54 \\
\hline $0.02($ EMC) & 19 & 35 & 48 \\
\hline SuperBlend & 20 & 30 & 45 \\
\hline
\end{tabular}

temperature, temperature, dew point temperature, 10-m wind, 10-m wind gust, and significant wave heights. These calculations are completed once per day using the most up-to-date URMA ground truth, and applied to forecasts from 1 to 264 hours. 18-hour maximum and minimum temperatures/humidity guidance is valid over a period while all other weather elements are valid at an instant in time.. The NBM, RTMA/URMA, and NWS Weather Forecast Offices (WFO) leverage the same high-resolution unified terrain data set to ensure that all users of these data have an identical reference starting point (University Corporation for Atmospheric Research \{UCAR\}, 2016).

The bias correction of the various model inputs are calculated and applied to each individual input. The bias corrected forecast is then weighted based on the dynamic weightings, and combined for a final deterministic forecast. The only exception to this process is sky cover, where the MAE is used to assign dynamic weights although the sky cover inputs are not bias corrected. We expect to bias correct sky cover using URMA after future upgrades when better nighttime first guess fields from Geostationary Operational Environmental Satellite (GOES) 16/17 satellite imagery are incorporated into the URMA analysis. Table 3 provides a list of the 64 forecast elements that will be available with NBM v3.2.

\section{Analysis and Discussion}

\section{a. The Core Elements}

Elements related to temperature, dewpoint, relative humidity, and sky cover are examples of the core elements where dynamic weighting based on MAE is performed. They are calculated through 264 hours each hour by blending the bias corrected components. Wind speed, wind direction, and wind gusts are often included among this group of core elements, but wind speed and gusts will be discussed in detail in a later section as the bias correction process is more complex.

Maximum and minimum temperature and relative humidity are initially calculated using 6-hour values available from the direct model output. If 6-hour maximum/minimum values are not available, the highest or lowest hourly values during the period of interest are used instead. Since URMA produces these four parameters, the NBM bias corrects to the URMA values independent of the process of bias correction for hourly temperature and relative humidity. The definition of these maximum/minimum fields is below:

- Maximum temperature is the 18-hour value from 1200 UTC to 0600 UTC (Day 2).

- Minimum temperature is the 18 -hour value from 0000 UTC to 1800 UTC.

- Maximum relative humidity is the 12 -hour value from $0600 \mathrm{z}$ UTC to 1800 UTC for most sectors, and 1200 UTC to 0000 UTC (Day 2) for the Guam sector.

- Minimum relative humidity is the 12-hour value from 1800 UTC to 0600 UTC (Day 2) for most sectors, and 0000 UTC to 1200 UTC for the Guam sector.

Other derived parameters such as apparent temperature use the NBM temperature, dewpoint, and wind speed information to calculate the appropriate heat index or wind chill values.

Performance of the NBM is closely tracked using baselines of skill such as NDFD forecasts and GMOS guidance. Bulk verification compares to URMA for 
Table 3. List of 64 forecast elements created for the NBM.

\begin{tabular}{|c|c|c|c|c|c|c|c|}
\hline Temp & Moisture & Precip & Wind & Winter & Fire & Aviation & Marine \\
\hline Temperature & \begin{tabular}{|l} 
Relative \\
Humidity \\
(RH)
\end{tabular} & QPF 1 hour & $\begin{array}{l}\text { 10-m wind } \\
\text { dir and speed }\end{array}$ & $\begin{array}{l}\text { Snow Amount } \\
1 \text { hour }\end{array}$ & $\begin{array}{l}\text { Haines } \\
\text { Index }\end{array}$ & Sky Cover & $\begin{array}{l}\text { Sig Wave } \\
\text { Height }\end{array}$ \\
\hline Max Temp & Max RH & QPF 6 hour & $\begin{array}{l}10-\mathrm{m} \\
\text { wind gust }\end{array}$ & \begin{tabular}{|l|} 
Snow Amount \\
6 hour
\end{tabular} & \begin{tabular}{|l|} 
Fosberg \\
Index
\end{tabular} & Ceiling & \begin{tabular}{|l} 
Freezing \\
Spray
\end{tabular} \\
\hline Min Temp & Min RH & QPF 12 hour & $\begin{array}{l}30-\mathrm{m} \\
\text { wind speed }\end{array}$ & $\begin{array}{l}\text { Snow Amount } \\
24 \text { hour }\end{array}$ & $\begin{array}{l}\text { Solar } \\
\text { Radiation }\end{array}$ & Visibility & PMSL \\
\hline $\begin{array}{l}\text { Apparent } \\
\text { Temp }\end{array}$ & $\begin{array}{l}\text { Dew Point } \\
\text { Temp }\end{array}$ & QPF 24 hour & $\begin{array}{l}80-\mathrm{m} \\
\text { wind speed }\end{array}$ & $\begin{array}{l}\text { Ice Amount } \\
1 \text { hour }\end{array}$ & $\begin{array}{l}\text { Mixing } \\
\text { Height }\end{array}$ & $\begin{array}{l}\text { Lowest } \\
\text { Cloud Base }\end{array}$ & \\
\hline \multirow[t]{13}{*}{ Water Temp } & & $\begin{array}{l}\text { Precipitation } \\
\text { Duration }\end{array}$ & & $\begin{array}{l}\text { Ice Amount } \\
6 \text { hour }\end{array}$ & $\begin{array}{l}\text { Transport } \\
\text { wind }\end{array}$ & Echo Tops & \\
\hline & & PoP01 & & $\begin{array}{l}\text { Ice Amount } 24 \\
\text { hour }\end{array}$ & $\begin{array}{l}\text { Ventilation } \\
\text { Rate }\end{array}$ & VIL & \\
\hline & & PoP06 & & $\begin{array}{l}\text { Cond prob of } \\
\text { Snow }\end{array}$ & $\begin{array}{l}3 \text { hour prob } \\
\text { of Thunder }\end{array}$ & $\begin{array}{l}\text { Max Hourly } \\
\text { Reflectivity }\end{array}$ & \\
\hline & & PoP12 & & Cond prob of Rain & & $\begin{array}{l}\text { LLWS Dir } \\
\text { and Speed }\end{array}$ & \\
\hline & & $\begin{array}{l}\text { Predominant } \\
\text { Weather }\end{array}$ & & Cond prob of Sleet & & $\begin{array}{l}\text { LLWS } \\
\text { Height }\end{array}$ & \\
\hline & & & & \begin{tabular}{|l|} 
Cond prob of \\
Freezing Rain \\
\end{tabular} & & Elrod Index & \\
\hline & & & & $\begin{array}{l}\text { Cond prob of } \\
\text { refreezing sleet }\end{array}$ & & $\begin{array}{l}\text { Mountain } \\
\text { Wave } \\
\text { Turbulence }\end{array}$ & \\
\hline & & & & $\begin{array}{l}\text { Probability of ice } \\
\text { present }\end{array}$ & & SBCAPE & \\
\hline & & & & Max Tw aloft & & $\begin{array}{l}1 \text { hour prob } \\
\text { of } t \text {-storm }\end{array}$ & \\
\hline & & & & $\begin{array}{l}\text { Pos Energy of } \\
\text { Warm Layer } \\
\text { (Bourgouin) } \\
\end{array}$ & & $\begin{array}{l}3 \text { hour prob } \\
\text { of t-storm }\end{array}$ & \\
\hline & & & & $\begin{array}{l}\text { Neg Energy of } \\
\text { Cold Layer (Bour- } \\
\text { gouin) }\end{array}$ & & $\begin{array}{l}12 \text { hour prob } \\
\text { of t-storm }\end{array}$ & \\
\hline & & & & Snow Level & & & \\
\hline & & & & $\begin{array}{l}\text { Snow to liquid } \\
\text { ratio }\end{array}$ & & & \\
\hline
\end{tabular}

gridded forecasts at about 3.7 million grid points for the CONUS. URMA is used as the gridded analysis of truth to which all gridded guidance and forecasts are verified against. To evaluate the performance of NBM guidance at select stations, primarily for Terminal Aerodrome Forecasts (TAFs), 1,319 Meteorological Terminal Aviation Routine (METAR) stations are also used for verification. Figure $2 \mathrm{a}$ shows gridded temperature verification versus URMA for NBM, GMOS, and
NDFD from the 11-month period of October 2018 through August 2019. Figure 2b is the same, except for station-based verification versus METARs. Whether using URMA or METAR data as ground truth, the MAE for the NBM is lower than GFS MOS and GMOS.

Figures $2 \mathrm{c}$ and $2 \mathrm{~d}$ also indicate that the surface temperature bias of the NBM is close to zero, even when compared to either GFS MOS or GMOS. Results for dew point temperature, relative humidity, 

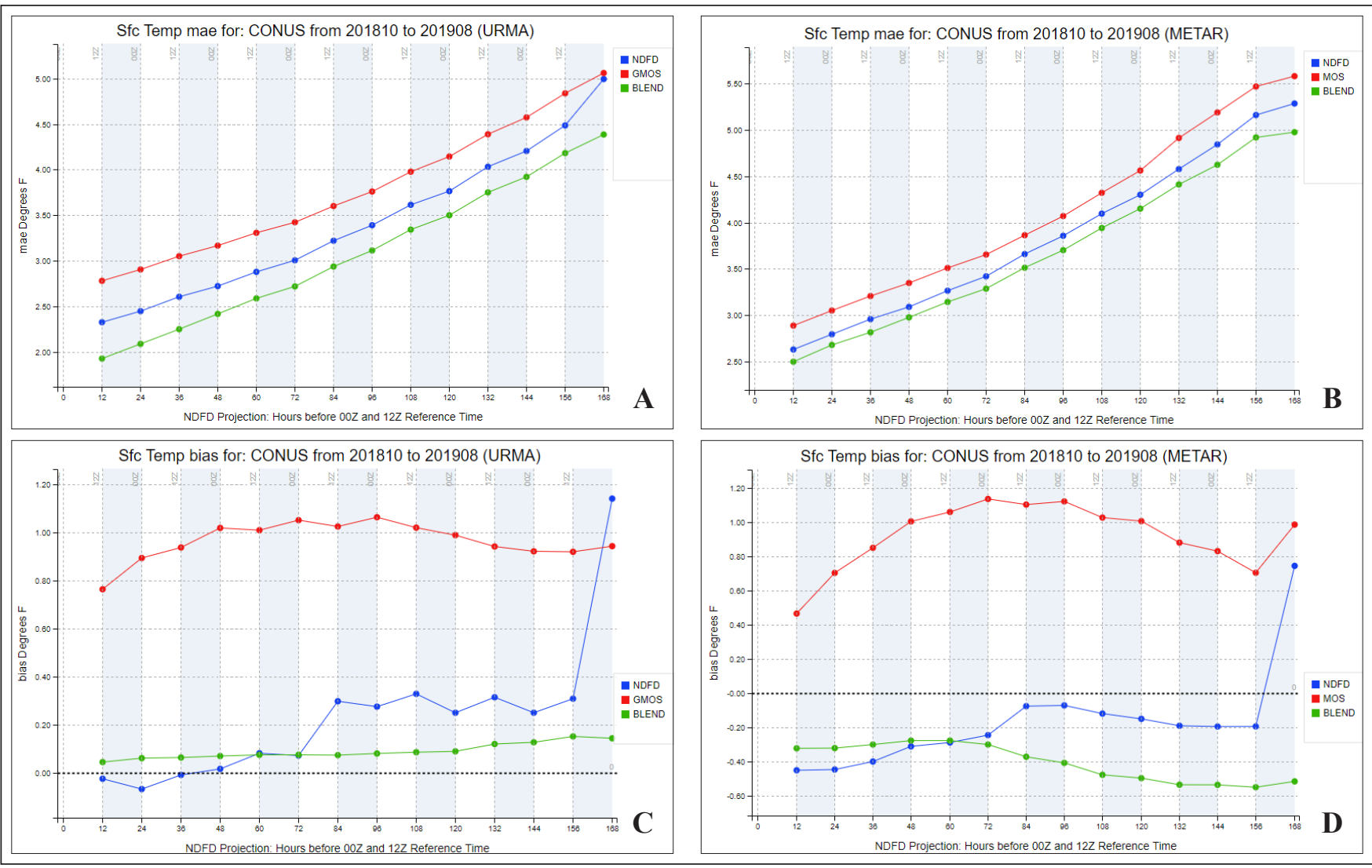

Figure 2. (A) Gridded temperature verification versus URMA for NBM (BLEND), GMOS, and NDFD from the eleven month period October 2018 to August 2019. (B) As in Fig. 2a, except using 1319 CONUS METARs as ground truth. (C) As in Fig. 2a, except for temperature bias. (D) As in Fig. 2a, except for temperature bias.

and significant wave height (not shown) also show bias values near zero. This is one of the advantages of performing bias correction to observations in real-time - an inherent advantage that MOS guidance does not possess.

Table 4 shows a matrix of relative performance versus NDFD of the Day 1-3 NBM forecasts for the meteorological winter months of December 2018-February 2019. Although performance is comparable for the CONUS, the NBM shows much better skill for the outside the CONUS (OCONUS) areas of Alaska, Hawaii, and Puerto Rico. Analogous results are found for Days 4-7 (Table 5). When using URMA as ground truth, the error statistics heavily favor the NBM rather than the NDFD. However, the error statistics are similar when compared with point-based METAR observations. Although these METAR-based stats at 1,319 stations only represent about $0.04 \%$ of the total grid points, they are representative of populated areas and airports.

The NBM accuracy is far better than GMOS for nearly every element in every sector at all forecast projections. Figures 3a-3j compare MAE scores (Heidke Skill Score for Sky Cover and Brier Score for PoP12) between NBM and GMOS for the period March 2017 to August 2019 for the CONUS domain using URMA as ground truth. With hourly updates, the NBM provides an excellent starting point for deterministic forecasts by incorporating the most recent NWP.

\section{b. Fire Weather Elements}

The Fire Weather Program is one of 11 National Service Programs in the NWS. A set of requirements for gridded forecasts from NBM to support Fire Weather related forecasts, watches, and warnings were provided and can be found in Table 3 . There are a total of 12 elements from a combination of core elements and fire weather elements. The primary inputs are temperature, relative humidity, wind speed, and mixing height.

Mixing height represents the top of the planetary boundary layer (PBL) and is calculated using a modified Stull Method (Stull, 1991). Some of the 11 total fire weather NBM inputs influence or are associated with 
Table 4. Relative performance of NBM v3.1 for December 2018 to February 2019 for the CONUS, Alaska (AK), Hawaii (HI), and Puerto Rico (PR) versus NDFD for Day 1-3 forecasts. Ground truth is station based against METAR (left columns) or gridded versus URMA (right columns). Much better is $10 \%+$ improvement, better is $5-9 \%$ improvement, and similar is within + or $-4 \%$.

\begin{tabular}{|c|c|c|c|c|c|c|c|c|c|}
\hline Day 1-3 & $\begin{array}{l}\text { CONUS } \\
\text { METAR }\end{array}$ & $\begin{array}{l}\text { CONUS } \\
\text { URMA }\end{array}$ & $\begin{array}{c}\text { AK } \\
\text { METAR }\end{array}$ & $\begin{array}{c}\text { AK } \\
\text { URMA }\end{array}$ & $\begin{array}{c}\text { HI } \\
\text { METAR }\end{array}$ & $\begin{array}{c}\text { HI } \\
\text { URMA }\end{array}$ & $\begin{array}{c}\text { PR } \\
\text { METAR }\end{array}$ & $\begin{array}{c}\text { PR } \\
\text { URMA }\end{array}$ & \\
\hline \multicolumn{10}{|l|}{ MaxT } \\
\hline \multicolumn{10}{|l|}{$\operatorname{Min} \mathrm{T}$} \\
\hline \multicolumn{10}{|l|}{ Temp } \\
\hline $\mathrm{Td}$ & & & & & & & & & NBM Much Better \\
\hline $\mathrm{RH}$ & & & & & & & & & NBM Better \\
\hline PoP12 & & & & & & & & & Similar \\
\hline QPF06HSS & & & & & & & & & NDFD Better \\
\hline QPF06CSI & & & & & & & & & NDFD Much Better \\
\hline Snow06 & & & & & & & & & $\mathrm{N} / \mathrm{A}$ \\
\hline \multicolumn{10}{|l|}{ Sky } \\
\hline \multicolumn{10}{|l|}{ WindDir } \\
\hline \multicolumn{10}{|l|}{ WindSpeed } \\
\hline \multicolumn{10}{|l|}{ WindGust } \\
\hline Wave Height & & & & & & & & & \\
\hline
\end{tabular}

Table 5. As in Table 4, except for Day 4-7 forecasts.

\begin{tabular}{|c|c|c|c|c|c|c|c|c|c|}
\hline Day 4-7 & $\begin{array}{l}\text { CONUS } \\
\text { METAR }\end{array}$ & $\begin{array}{l}\text { CONUS } \\
\text { URMA }\end{array}$ & $\begin{array}{c}\text { AK } \\
\text { METAR }\end{array}$ & $\begin{array}{c}\text { AK } \\
\text { URMA }\end{array}$ & $\begin{array}{c}\text { HI } \\
\text { METAR }\end{array}$ & $\begin{array}{c}\text { HI } \\
\text { URMA }\end{array}$ & $\begin{array}{c}\text { PR } \\
\text { METAR }\end{array}$ & $\begin{array}{c}\text { PR } \\
\text { URMA }\end{array}$ & \\
\hline \multicolumn{10}{|l|}{ MaxT } \\
\hline \multicolumn{10}{|l|}{$\operatorname{MinT}$} \\
\hline Temp & & & & & & & & & NBM Much Better \\
\hline $\mathrm{Td}$ & & & & & & & & & NBM Better \\
\hline $\mathrm{RH}$ & & & & & & & & & Similar \\
\hline PoP12 & & & & & & & & & NDFD Better \\
\hline Sky & & & & & & & & & NDFD Much Better \\
\hline WindDir & & & & & & & & & $\mathrm{N} / \mathrm{A}$ \\
\hline \multicolumn{10}{|l|}{ WindSpeed } \\
\hline Wave Height & & & & & & & & & \\
\hline
\end{tabular}

PBL height, which is also a reasonable estimate of the mixing height. An inventory of the lowest few kilometers of the model sounding information was taken to determine which models had sufficient resolution to either calculate the Stull Method or provide a PBL height. Transport wind speed is the average wind magnitude in the layer defined by the surface and the mixing height. Transport wind direction is determined by the vector of average $U$ (zonal velocity) and average $\mathrm{V}$ (meridional velocity) wind components in that same mixed layer. The product of the mixing height and the transport wind yields the ventilation rate, which is used to estimate the dispersion rate of smoke.

The lower atmosphere stability index or Haines Index (Haines, 1988) is also calculated using one of three calculations (low, middle, and high). Utilizing the $2.5 \mathrm{~km}$ unified terrain height as reference, the NBM calculates the Haines Index using the low equation for elevations below 1,000 $\mathrm{ft}$ mean sea level (MSL), the middle equation for elevations from 1,000 to $2,999 \mathrm{ft}$ MSL, and the high equation for elevations of 3,000 $\mathrm{ft}$ MSL and above. The Fosberg Index (1978) is also 


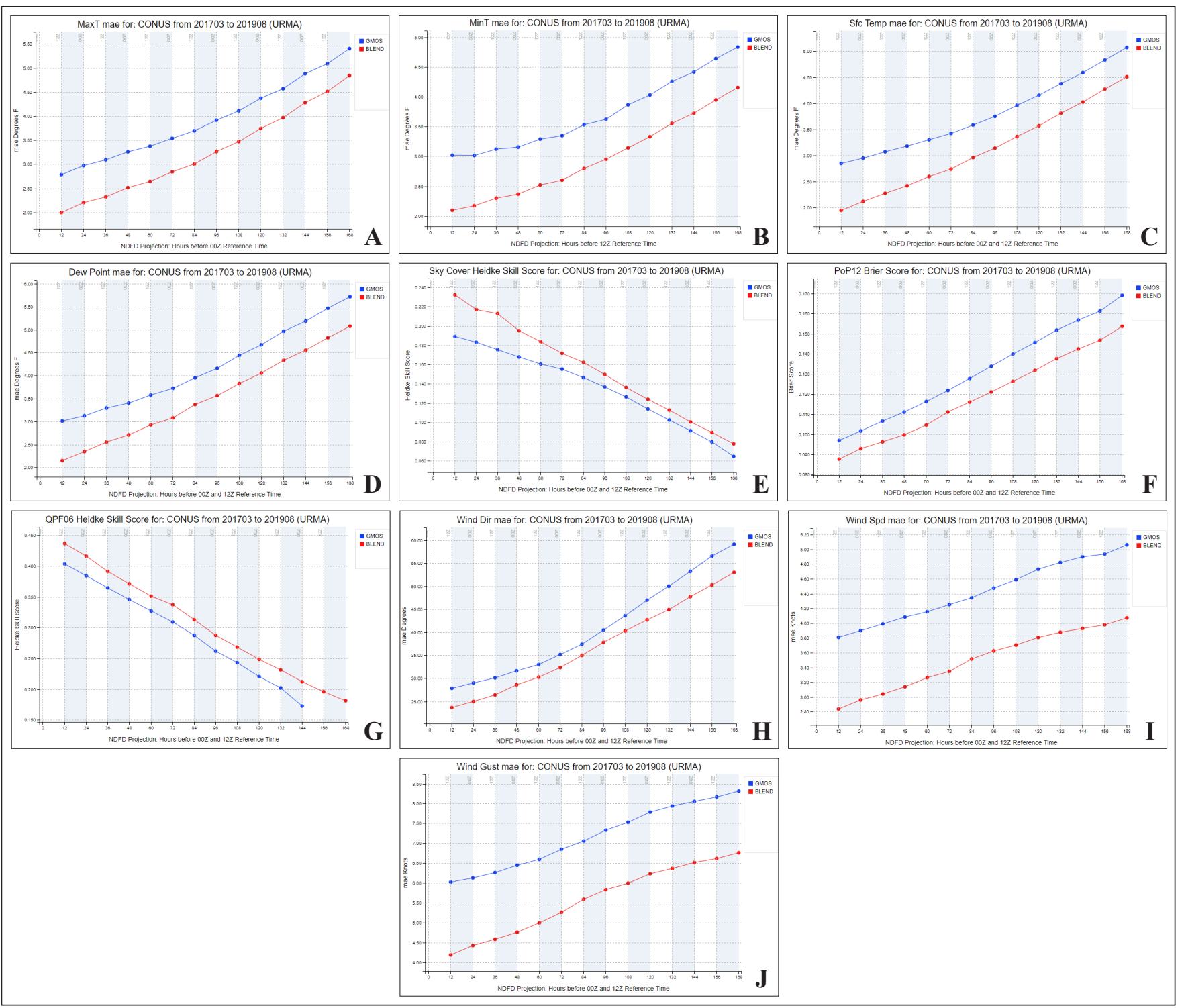

Figure 3. (A) Plot of maximum temperature MAE of NBM (Blend) in red and GMOS in blue for CONUS sector using URMA as ground truth for period of March 2017 to August 2019. (B) As in Fig. 3a, except for minimum temperature. (C) As in Fig. 3a, except for hourly temperature. (D) As in Fig. 3a, except for dew point temperature. (E) As in Fig. 3a, except for heidke skill score for sky cover. (F) As in Fig. 3a, except for brier score for PoP12. (G)As in Fig. 3e, except for QPF06. (H) As in Fig. 3a, except for wind direction. (I) As in Fig. 3a, except for wind speed. (J) As in Fig. 3a, except for wind gust.

calculated, using a combination of temperature, relative humidity, and wind speed. Rather than calculating a Fosberg Index for each model and then blending those values to yield a final blended Fosberg Index, the blended Fosberg Index is calculated by using its blended input variables.

\section{c. Winter Weather and Probability of Weather Types}

Deterministic snow and ice forecasts for 1-hour and 6-hour amounts were introduced for the CONUS and Alaska domains beginning with NBM v3.1. At that time, probabilities of rain, snow, sleet, and freezing rain (Probability of Weather Type - PoWT) were derived via a "top-down" approach employed by the NWS Central Region "Forecast Builder" application. This 
methodology assessed the presence of cloud ice in the precipitating cloud layer (ProbIcePresent), the elevated warm layer aloft (maximum value of web bulb potential temperature - MaxTw), and the surface-based cold layer (see Baumgardt et al. 2017 for more details). The probabilities were based on a mean sounding consisting of 18 NWP inputs. Snow and ice amounts were derived by parsing the NBM deterministic mean QPF into amounts for each type based on their respective PoWT ratios, and applying an equally-weighted mean snow-liquid ratio (SLR) and various NBM surface temperature thresholds. The "top-down" methodology was a good first step in providing deterministic snow and ice amounts in the NBM, but came with some drawbacks. The use of a mean sounding to derive PoWT resulted in sharp discontinuities in probabilities near the surface freezing line and occasionally produced extremely sharp gradients in snow accumulations. Also, an adjustment based on ProbIcePresent was assigning too much QPF to freezing drizzle especially in the dry slots of storms. This type of diagnosis does not fully account for important physical aspects of the thermal profiles - namely the depth of the melting and refreezing layers.

For NBM v3.2, three important changes were made. PoWT is now derived using a revised Bourgouin layer energy technique which calculates areas of positive melting energy and negative refreezing energy from the wet-bulb temperature profile, to determine the likelihood of rain vs. snow and freezing rain vs. ice pellets (see Lenning and Birk 2018 for more details). Probabilities are computed for each model individually based on relationships derived from local studies (e.g., Lenning and Birk 2018), and an expertweighted average is calculated from all model inputs (18 inputs in short-term and 8 inputs in extended) to produce a blended PoWT. Similarly, 1-hour and 6-hour

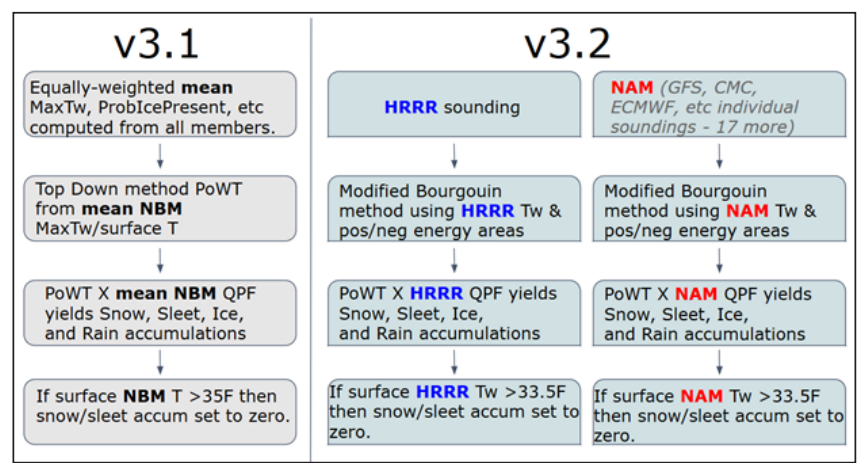

Figure 4. Comparison of PoWT and snow/ice amount methodologies for NBM v3.1 vs. v3.2. snow and ice amounts are computed individually for each model and then combined with expert weights to obtain blended deterministic snow and ice accumulations. A comparison of PoWT and snow/ice amount methodologies for v3.1 and v3.2 is illustrated in Fig. 4. Results for the v3.2 methodology seen during the 2018-19 winter season showed some significant improvements, which include:

1) More realistic gradients in PoWT.

2) A decrease in mean absolute error for 6-hour snow amount by up to $10 \%$ when subjectively verified against the National Operational Hydrologic Remote Sensing Center (NOHRSC) snowfall analysis during several events.

3) Improved snow forecasts around the snow level in complex terrain and in rain/snow transition zones.

In order to support a NWS probabilistic snow experiment, a variety of snow and ice percentiles and threshold probabilities were developed for v3.2 covering 24-, 48-, and 72-hour periods. These include:

(1) 5th, 10th, 25th, 50th, 75th, 90th, and 95th percentile snow amount

(2) 5th, 10th, 25th, 50th, 75th, 90th, and 95th percentile ice amount

(3) Probability of exceedance for snowfall $0.1,1$, $2,4,6,8,12,18,24$, and 30 inches

(4) Probability of exceedance for ice $0.01,0.1$, $0.25,0.5$, and 1.0 inches

The percentiles and threshold probabilities listed above are computed directly from the ranked membership without assuming a particular distribution. To increase spread in the extended range, the membership was supplemented with seven additional inputs derived using the 5th, 10th, 25th, 50th, 75th, 90th, and 95th percentiles of NBM QPF. An example forecast of 10th, 50th, and 90th percentile snow amount is shown in Fig. 5 for an event in the Sierra Nevada Mountains. Compared to v3.1 mean snowfall (top-left), the percentiles are more realistic and more closely match the amount observed at Lake Tahoe with this event (6-10" range). 


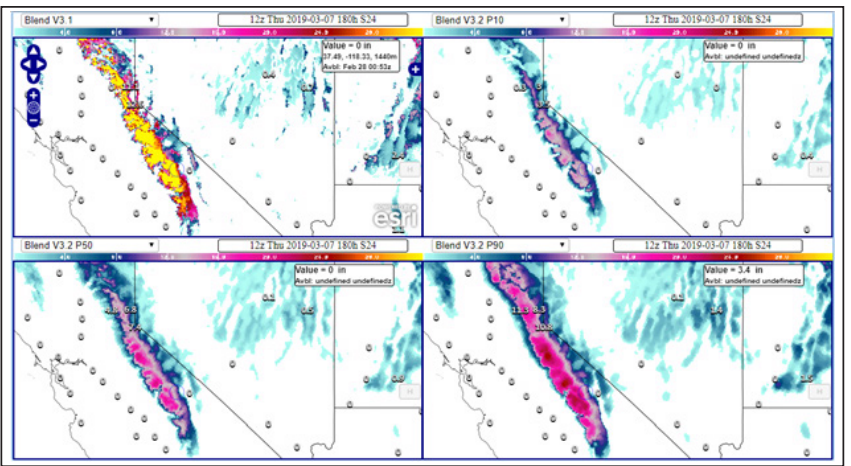

Figure 5. Example 180-hour NBM forecast of snow amount percentiles, showing v3.1 mean snowfall (top-left), v3.2 10th percentile (top-right), v3.2 50th percentile (bottom-left), and v3.2 90th percentile (bottom-right).

\section{d. Probability of Thunderstorms}

Guidance for the probability of a thunderstorm (hereafter "ProbThunder") for 3-hour periods out to 84 hours over the CONUS was introduced in NBM v3.0 and was comprised only of Short Range Ensemble Forecast (SREF)-based calibrated thunderstorm probabilities produced on WCOSS by the Storm Prediction Center (SPC) (see Bright et al. 2005 for more details on the SREF-based product). In NBM v3.1, ProbThunder for 3-h and 12-h periods through 84 hours for CONUS was produced from an expert-weighted blend of SREFbased (SPC) probabilities and GFS-based GMOS probabilities (e.g., Shafer and Gilbert 2008), with SREF given $67 \%$ weight and GMOS $33 \%$ weight. The SREF and GMOS products both define the occurrence of a thunderstorm as one or more cloud-to-ground (CG) flashes in a 40-km grid box. Additionally, SPC SREFbased calibrated thunderstorm probabilities for $1-\mathrm{h}$ periods out to 36 hours was added to NBM v3.1.

For NBM v3.2, the following enhancements will be implemented for ProbThunder:

(1) New membership for 1-h ProbThunder CONUS. Localized Aviation MOS Program (LAMP) 1-h probability of lightning through 25 hours over the CONUS (described in Charba et al. 2017) will be added as a component for NBM 1-h ProbThunder. The LAMP product incorporates output from the HRRR, MultiRadar Multi-Sensor(MRMS) and total lightning observations as predictors, providing enhanced skill especially in the first 6-9 hours. The LAMP and SPC SREF products will each be weighted $50 \%$ for 1 -h ProbThunder, which is expected to result in improved skill and spatial detail compared to the operational v3.1 SREFonly product.

(2) New membership for 3-h/12-h ProbThunder CONUS. Recently refreshed GFS MOS, NAM MOS, and ECMWF MOS components were developed and added to the membership for 3-h and 12-h ProbThunder over the CONUS. The new MOS systems use total lightning (in-cloud and CG) data to define the occurrence of a thunderstorm in a 40-km grid box, and use climatology and various model-derived parameters as predictors (see Shafer and Rudack 2015 for a more detailed description of a typical MOS development for probability of thunder). Aviation customers are also concerned with in-cloud (IC) lightning and not just CG, thus the switch to a total lightning definition for the MOS components will result in a blended product that better serves aviation users.

\section{e. Wind Speed and Wind Gust elements}

To date, the NBM weights and bias corrects both wind speed and wind gusts unconditionally. That is to say, the bias correction factor (BCF) and mean absolute error weighting factor (MAEWF) (that is used to correct today's raw model guidance) is independent of the magnitude of the wind speeds used in generating the $\mathrm{BCF}$ and MAEWF. In most instances this unconditional adjustment works quite well because wind speeds are generally low. However, when windier situations do occur there is no discernable signal in the BCF and MAEWF to appropriately bias correct these anomalous wind speeds and those non-anomalous wind speeds immediately following the event. To resolve this issue, we have begun stratifying the BCF and MAEWF into specific categories (Table 6) that correspond to specific NWS wind hazard categories.

Prior to binning the model forecasts we identify areas of pronounced local terrain features such as ridgetops at the NBM grid resolution by comparing the elevation of each gridpoint to the average elevation in its vicinity. We do so by subtracting the elevation at each grid point in the high resolution unified terrain data set from the same smoothed grid point at a coarser spatial resolution of approximately $65 \mathrm{~km}$ (Fig. 6). Those raw model wind speeds collocated with grid points of 
Table 6. The five wind speed and wind gust categories (units of meters per second) for which BCF and MAEWF are calculated and used to bias correct the most current raw model's input guidance.

\begin{tabular}{|c|c|c|}
\hline Category Name & Low Bound & High Bound \\
\hline No Advisory & 0 & $9.5(21.2 \mathrm{mph})$ \\
\hline Small Craft Advisory & $9.5(21.2 \mathrm{mph})$ & $17(38.02 \mathrm{mph})$ \\
\hline Gale Warning & $17(38.02 \mathrm{mph})$ & $24.5(54.80 \mathrm{mph})$ \\
\hline Storm Warning & $24.5(54.80 \mathrm{mph})$ & $32.5(72.7 \mathrm{mph})$ \\
\hline Hurricane Force Wind Warning & $32.5(72.7 \mathrm{mph})$ & N/A \\
\hline
\end{tabular}

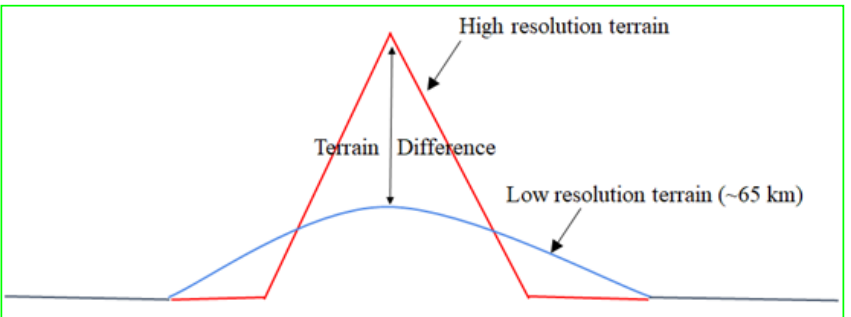

Figure 6. Schematic diagram of identifying areas of pronounced terrain for inflating wind speeds.

pronounced terrain differences are inflated by a formula arrived at through empirical testing.

$$
\text { Inflated Wind Speed }=\beta_{W G} * W G+\left(1-\beta_{W G}\right) * W S
$$

Where $\beta_{\mathrm{WG}}=$ Weight assigned to the wind gust

$\mathrm{WG}=$ Raw model wind gust after interpolation to NBM grid

WS=Rawmodelwindspeedafterinterpolationto NBM grid

Where $\beta_{\mathrm{wG}}=($ For TDIFF $>50$ Meters $)=$ Minimum $(1, \mathrm{TDIFF} / 200)$

$\beta_{\mathrm{WG}}=($ For TDIFF $<50$ Meters $)=0$

and $\quad$ TDIFF $=$ (High Resolution Elevation-Low Resolution Elevation)

We inflate wind speeds in areas of pronounced terrain by the model's raw wind gust through a weighting factor $\beta_{\mathrm{WG}}$. $\beta_{\mathrm{WG}}$ is determined by a minimum function yielding one of two possible values: (1) the ratio of the model terrain difference to a factor of 200 or (2) the value of 1 . The smaller of the two values is assigned to $\beta_{\mathrm{W}}$ to that grid point and the inflated wind speed is calculated using equation (3). In NBM v3.1 wind speeds were inflated after all inputs were blended. This methodology overall works well; however, there are instances when the wind speeds over ridge tops were unrealistically high. Extensive testing has demonstrated that by inflating individual raw model wind speeds prior to their blending and binning the wind speeds before being bias corrected removes the likelihood of this scenario occurring.

Essentially, the algorithm works in the following manner for each input model cycle, projection, and gridpoint: First, the raw wind speed is inflated using the same methodology as in v3.1 in areas of higher terrain. In areas where terrain is a nonissue the raw wind speeds are unaltered. Raw wind gusts are not inflated irrespective of terrain. Second, these (inflated) wind speeds (or wind gusts) are sampled and placed into one of five bins. Third, for a specific category, the BCF and MAEWF is updated based upon the most recent URMA observation. Only the wind speed (wind gust) for that category is updated with new values - all other categories remain unchanged. In this way, only wind speeds (wind gusts) with specific thresholds are modified and do not adversely affect the future corrections of the remaining wind speeds (wind gusts) categories. Fourth, all bias corrected wind speeds (wind gusts) are then weighed against all other inputs and then blended. Stratifying in this manner will likely not only benefit the calibration of windier events but also benefit the calibration of non-anomalous wind conditions that immediately follow.

Figure 7 shows NDFD, NBM v3.1, NBM v3.2, $10 \mathrm{~m}$ wind, 24-hour forecasts issued on May 20, 2019, alongside the verifying URMA analysis for the southwestern United States. While this wind event is not significant it does demonstrate that the NBM v3.2 wind speeds are more muted than NBM v3.1 over the ridge tops in the Sierra Cascades. The verifying URMA analysis difference fields shown in Fig. 8 (upper two panels and lower right panel in Fig. 8) underscores this point by highlighting the smaller wind speed 


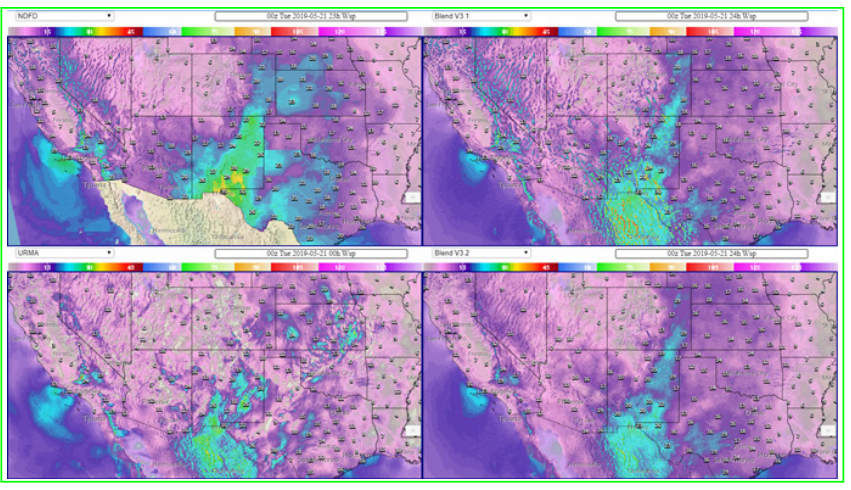

Figure 7. May 20, 2019, 24-hour, $10 \mathrm{~m}$ wind speed forecasts in the Southwest United States for NDFD (upper left), NBM v3.1 (upper right), NBM v3.2 (lower right), and the verifying URMA analysis (lower left).

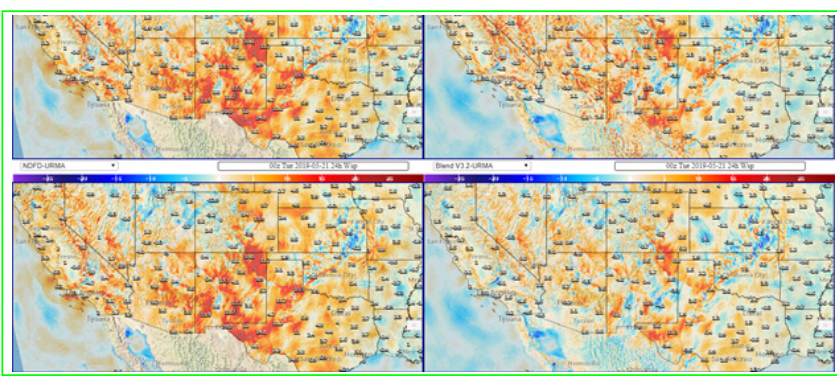

Figure 8. Forecast-Analysis difference fields for 24-hour, $10 \mathrm{~m}$ wind speed forecasts shown in Fig. 7 using the verifying URMA analysis valid 0000 UTC May 212019.

differences with lighter colors in the lower right panel when compared to the two upper panels. Similar results are noted for wind gust forecasts (not shown).

Bulk NBM v3.2 $10 \mathrm{~m}$ wind speed MAE verification for March 2019 for both the CONUS and western CONUS (Fig. 9a and 9b) also shows a notable improvement in scores over NBM v3.1 especially in the medium range. NBM v.3.1 $10 \mathrm{~m}$ wind gust verification for March 2019 also demonstrates an improvement over NBM v.3.1 for the western CONUS (Fig. 9c). However, the CONUS-wide verification for $10 \mathrm{~m}$ wind gusts are more mixed (not shown) with NBM v3.1 still generally displaying better MAE (on the order of 0.2-0.4 kt) in the medium range. The improvement of NBM wind speed and wind gust guidance can likely be attributed to a combination of modifying the terrain-inflation of wind speeds and stratifying the bias correction and MAE weighting of wind speeds and wind gusts. With future adequate sampling of the windier months of fall, winter, and spring, we believe the binning methodology will become a more influential component of this algorithm
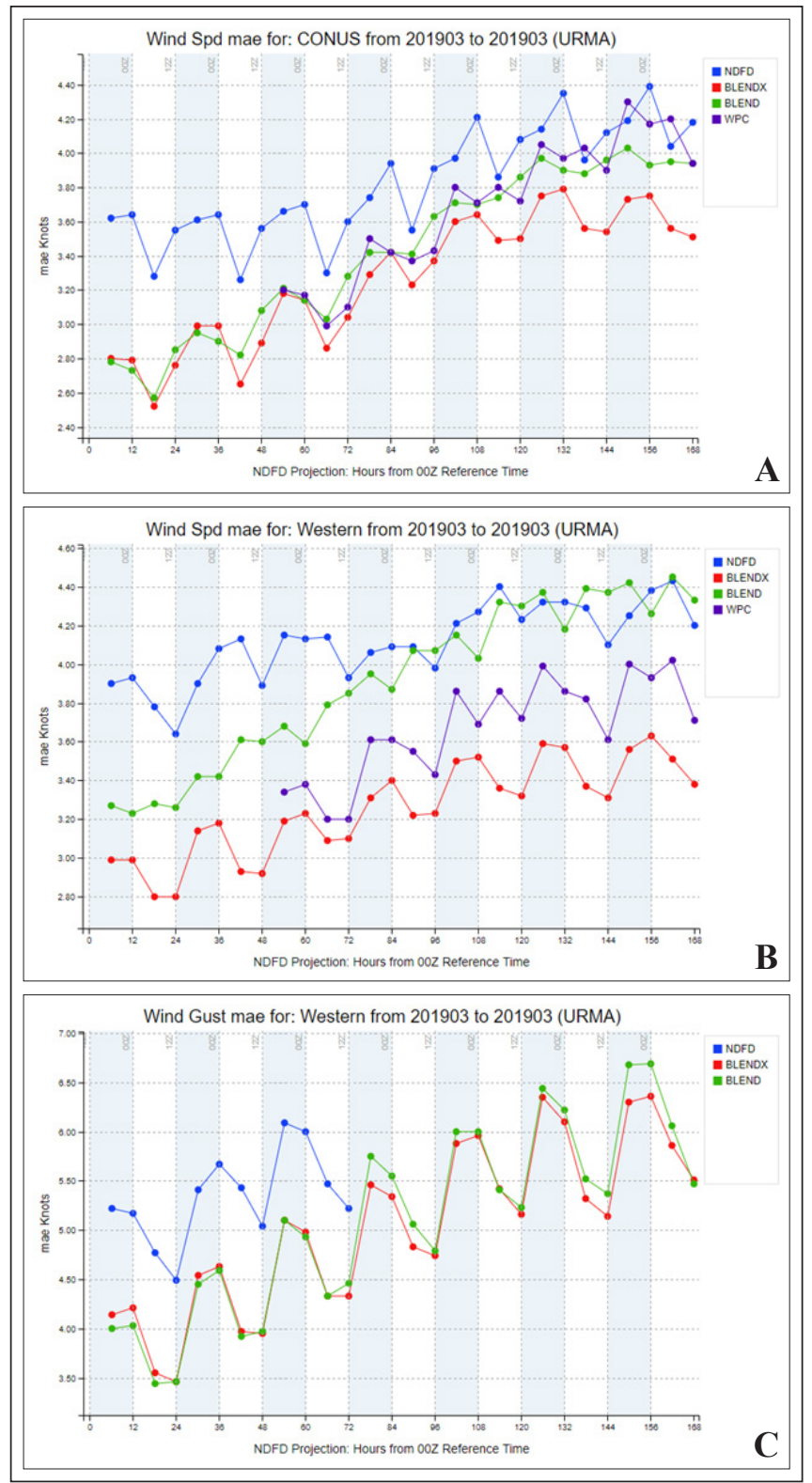

Figure 9. (A) MAE bulk verification scores for 10 $\mathrm{m}$ wind speed for the United States for March 2019 forecasts valid at 0000 UTC. In the legends below, "BLEND" refers to NBM v3.1 and "BLENDX" refers to NBM v3.2. (B) Same as Fig. 9a except for the western United States. (C) Same as Fig. 9b except for wind gust.

and will continue to improve the accuracy of NBM wind speeds and wind gusts.

\section{Conclusions}

Blending high-resolution URMA bias-corrected multi-model deterministic and ensemble-based guidance produces more skillful guidance than NDFD 
forecasts in both gridded and station based verification. The process of downscaling information from coarser global models adds detail in areas of complex terrain.

The NBM updates each hour with the latest NWP information. Although historically we have had forecast packages that are updated two to four times per day, the NBM acts as a flywheel of forecast information that is constantly refreshing and updating during the course of a day.

Although the NBM does perform well in deterministic forecasts, the real power of multi-model ensembles and post processing is the ability to produce calibrated probabilistic information for use in ImpactBased Decision Support Services. There is uncertainty in every forecast, and it is difficult to produce a deterministic forecast that represents all the potential outcomes. Providing more information about the most likely scenarios and potential alternative outcomes should help core customers make better decisions.

Acknowledgments: A special thanks to Robert James, Eric Engle, Carly Buxton, Cassie Stearns, Michael Baker, Daniel Nielson, and Scott Scallion to their major contributions to the WCOSS code. We thank the two thorough anonymous reviewers of the manuscript and their many useful suggestions that improved the content.. Thanks also to Bruce Veenhuis, Tamarah Curtis, Geoff Wagner, Andrew Benjamin, Justin Wilkerson, Yun Fan, Christina Finan, James $\mathrm{Su}$, and Wei Yan for their contributions to the code. We also thank a great deal of subject matter experts and contributors (far too many to list in total): John Wagner, Tabitha Huntemann, Dana Strom, Linden Wolf, Brian Miretzky, Kathyrn Gilbert, David Ruth, David Myrick, David Novak, James Nelson, Mark Klein, Jerry Wiedenfeld, Andrew Just, Dan Baumgardt, Eric Lenning, Kevin Birk, Matthew Jeglum, the members of the NBM Science Advisory Group, the Nation Service Program Leads and Teams, Darren Van Cleave, the NWS Regional Scientific Services Divisions, Bob Glahn, Stephan Smith, William Bua, Ming Ji, and Chris Strager.

\section{REFERENCES}

Baumgardt, D., Just A., and P. E. Shafer, 2017: Deriving precipitation type probabilities in the National Blend of Models. Poster, 28th Conference on Weather Analysis and Forecasting / 24th Conference on Numerical Weather Prediction, Seattle, WA, Amer. Meteor. Soc., CrossRef.

Benjamin, S. G., and Coauthors, 2016: A North American hourly assimilation and model forecast cycle: The Rapid Refresh. Mon. Wea. Rev., 144, 1669-1694, CrossRef.

Baars, J. A, and C. F. Mass, 2005: Performance of National Weather Service forecasts compared to operational, consensus, and weighted Model Output Statistics, Wea. Forecasting, 20,1034-1047, CrossRef.

Bright, D.R., Wandishin, M.S., Jewell, R.E., Weiss, S.J., 2005. A physically based parameter for lightning prediction and its calibration in ensemble forecasts. Preprints, Conf. on Meteo. Appl. of Lightning Data. San Diego, CA, Amer. Meteor. Soc., 4.3. CrossRef.

Charba, J. P., F. G. Samplatsky, P. E. Shafer, J. E. Ghirardelli, and A. J. Kochenash, 2017: Experimental upgraded LAMP convection and total lightning probability and "potential" guidance for the CONUS. Preprints, $18 t h$ Conference on Aviation, Range, and Aerospace Meteorology, Seattle, WA, Amer. Meteor. Soc., 2.4. CrossRef.

Cui, B., Z. Toth, Y. Zhu, and D. Hou, 2011: Bias correction for global ensemble forecast, Wea. Forecasting, 27,396410, CrossRef.

De Pondeca, M. S. F, G. S. Manikin, G. DiMego, S. G. Benjamin, D. F. Parrish, R. J. Purser, W.S. Wu, J. D. Horel, D. T. Myrick, Y. Lin, R. M. Aune, D. Keyers, B. Colman, G. Mann, and J. Vavra, 2011. The Real-Time Mesoscale Analysis at NOAA's National Centers for Environmental Prediction: Current status and development. Wea. Forecasting, 26, 593-612. CrossRef.

Fosberg, M. A., 1978: Weather in wildland fire management: The fire weather index. Conference on Sierra Nevada Meteorology, pp. 1-4, June 19-21 Lake Tahoe, CA.

Gagan, J., C. Greif, G. Izzo, J. P. Craven, J. Martin, J. Green, M. Kreller, R. Khron, R. Berdes, 2009: NWS Central Region Grid Methodology Advisory Team Final Team Report, NWS CRH Scientific Services Division, 17 pp.

Glahn, H. R and D. P. Ruth, 2003: The New Digital Forecast Database of the National Weather Service. Bull. Amer. Meteor. Soc., 84, 195-202. CrossRef. , K. Gilbert, R. Cosgrove, D. P. Ruth, and K. Sheets, 2009. The Gridding of MOS. Wea. Forecasting, 24, 520529. CrossRef.

, 2013. A comparison of two methods of bias correcting MOS temperature and dewpoint forecasts. MDL Office Note 13-1, 22 pp.

Goerss, J. S., 2007a: Prediction of consensus tropical cyclone track forecast error. Mon. Wea. Rev., 135, 1985-1993. CrossRef. 
Greif, C., J. Wiedenfeld, A. Just, 2017: Central Region ForecastBuilder experiment summary report, NWS CRH Scientific Services Division, 35 pp.

Haines, D.A. 1988. A lower atmospheric severity index for wildland fires. Natl. Wea. Dig. 13(3): 23-27.

Hamill, T,M., E. Engle, D. Myrick, M. Peroutka, C. Finan, and M. Scheurer, 2017: The U.S. National Blend of Models for statistical postprocessing of probability of precipitation and deterministic precipitation amounts, Mon. Wea. Rev., 145, 3441-3463, CrossRef.

, and Scheuerer, M., 2018: Probabilistic precipitation forecast postprocessing using quantile mapping and rank-weighted best-member dressing. Mon. Wea. Rev., 146, 4079-4098. CrossRef.

, 2019: Practical aspects of statistical postprocessing. Statistical Postprocessing of Ensemble Forecasts, S. Vannitsem, D. Wilks, and J. Messner, Eds., Elsevier, 187-217. CrossRef.

Lenning, E., and K. Birk, 2018: A revised Bourgouin precipitation-type algorithm [Recorded Presentation]. 29th Conference on Weather Analysis and Forecasting, Denver, CO, Amer. Meteor. Soc., 3A.5. CrossRef.

Shafer, P. E., and K. K. Gilbert, 2008: Developing GFSbased MOS thunderstorm guidance for Alaska. Preprints, 3rd Conference on Meteorological Applications of Lightning Data, New Orleans, LA, Amer. Meteor. Soc., P2.9. CrossRef. , and D. E. Rudack, 2015: Development of a MOS thunderstorm system for the ECMWF model. Seventh Conference on the Meteorological Applications of Lighting Data, Phoenix, AZ, Amer Meteor. Soc., 2.1. CrossRef.

Stern, A. D., 2018: NWS Directives 10-102, Products and services change management, $40 \mathrm{pp}$. CrossRef.

Stull, R. B., 1991: Static stability-an update. Bull. Am. Meteor. Soc., 72, 1521-1529, CrossRef.

Univ. Corp. for Atmos. Research (UCAR), Cooperative Program for Meteorological Education and Training, 2016: Unified Terrain in the National Blend of Models, training module. CrossRef.

Vislocky, R. L., and J. M. Fritsch, 1995: Improved model output statistics forecast through model consensus. Bull. Amer. Meteor. Soc., 76, 1157-1164. CrossRef.

Whitaker, J.S., X. Wei, and F. Vitart, 2006: Improving week2 forecasts with multimodel reforecast ensembles. Mon. Wea. Rev., 134, 2279-2284. CrossRef.

Zhou, X., Y. Zhu, D. Hou, Y. Luo, J. Peng, and R. Wobus, 2017: Performance of the New NCEP Global Ensemble Forecast System in a parallel experiment. Wea. Forecasting, 32, 1989-2004. CrossRef. 